49 patients taking treatment by mouth, however, only one developed primary ventricular fibrillation when in the CCU. As four of the five patients who developed late primary ventricular fibrillation did so within the first week after transfer and all died, there is a case for more-prolonged monitoring of diabetics with acute myocardial infarcts.

There is evidence both for $^{13}$ and against ${ }^{14}{ }^{15}$ adverse inotropic effects of sulphonylureas on the heart muscle. Further work is needed to clarify this effect, particularly in view of the evidence of increased mortality from ischaemic heart disease in patients taking antidiabetic drugs. ${ }^{16-19}$ Other factors such as diabetic control before admission may require consideration, since previous poor control appears to be an adverse factor in diabetics admitted to a CCU with acute myocardial infarction. Diabetic control in the CCU should be as good as possible, with earlier consideration for insulin treatment, as there is evidence that the ventricular fibrillation threshold is lowered in the presence of metabolic acidosis ${ }^{2}$ and raised free fatty acid levels. ${ }^{21}$

Despite our finding of an increased mortality $(24 \%)$ among diabetics admitted to a CCU as compared with among nondiabetics, this was considerably better than the $38^{\circ}{ }_{0}$ to $61 \%$ mortality ${ }^{13}$ recorded before the advent of coronary care units, and our results are not nearly so depressing as those of the Birmingham study $\left(35^{\circ} \%\right.$ ). We have also been unable to discover any definite adverse effect on the outcome of acute myocardial infarction (both primary ventricular fibrillation and mortality) from oral hypoglycaemic agents. Retrospective analyses are probably unlikely to give a clear answer to the effect of oral antidiabetic treatment on mortality in view of the relatively few patients concerned and the varying referral and admission policies of different centres.
We thank the physicians in charge of the CCU, Edinburgh Royal Infirmary, for advice and encouragement. Thanks are also due to Mrs Sadie Dickson, research assistant, and Miss Sheila M Gore, of the University of Edinburgh Medical Computing Group, for help with the statistical analyses.

Requests for reprints should be sent to Dr A D B Harrower.

\section{References}

${ }^{1}$ Bradley, R F, and Bryfogle, J W, American fournal of Medicine, 1956, 20, 207.

2 Sievers, J, Acta Medica Scandinavica, 1963, suppl No 406.

3 Partamian, J O, and Bradley, R F, New England Fournal of Medicine, $1965,275,455$.

4 Soler, N G, et al, Lancet, 1974, 1, 475.

${ }^{5}$ Harrower, A D B, and Clarke, B F, Lancet, 1974, 1, 749.

${ }^{6}$ Lawrie, D M, et al, Lancet, 1967, 2, 109.

7 Sloman, G, et al, in Symposium on Cardiac Arrhythmias, ed E Sandфe et al, p 677. Södertälje, AB Astra, 1970.

${ }^{8}$ Lawrie, D M, ct al, Lancet, 1968, 2, 523.

${ }^{9}$ Falconer, D S, et al, Annals of Human Genetics, 1971, 34, 347.

10 Pell, S, and D'Alonzo, C A, Fournal of the American Medical Association, $1970,214,1833$.

11 Bengtsson, C, Acta Medica Scandinavica, 1973, suppl No 549, p 65.

12 Mann, J L, et al, British Medical fournal, 1975, 1, 241.

13 Lasseter, K C, et al, fournal of Clinical Investigation, 1972, 51, 2429.

14 Crockett, S E, et al, Metabolism, 1974, 23, 763.

15 Young, J L, jun, et al, American Heart fournal, 1975, 89, 189.

16 University Group Diabetes Program, Diabetes, 1970, 19, suppl no 11, pp 747, 789.

17 Hadden, D R, et al, Lancet, 1972, 1, 335

18 Boyle, D, et al, Lancet, 1972, 1, 338

19 University Group Diabetes Program, Diabetes, 1975, 24, suppl no 1.

20 Gerst, P H, et al, Surgery, 1966, 59, 1050.

${ }^{21}$ Kurien, V A, and Oliver, M F, Lancet, 1970, 1, 813.

\title{
Attack rates of notified whooping cough in immunised and unimmunised children
}

\author{
NORMAN D NOAH
}

British Medical fournal, 1976, 1, 128-129

\section{Summary}

The incidence of whooping cough among immunised children under the age of six and among children of the same age who were not fully immunised was ascertained by analysing whooping-cough notifications from several health authorities. In the first three years of the study the results showed that attack rates were much higher in children who were not fully immunised than in those who were. This finding suggests that current vaccines provide young children with substantial protection against whooping cough.

\section{Introduction}

Pertussis vaccines were shown to be effective in Medical Research Council trials in $1948-52^{1-3}$ and were subsequently widely used. Later doubts about the continuing efficacy of the

Epidemiological Research Laboratory, Central Public Health Laboratory, Colindale Avenue, London NW9 5HT

NORMAN D NOAH, MB, MRCP, senior epidemiologist

vaccine $^{4-6}$ led to a Public Health Laboratory Service (PHLS) survey, ${ }^{i, *}$ which showed that much of the pertussis vaccine in general use for a few years before 1968 was not very effective. The vaccines now used differ from those assessed in the PHLS survey in being stronger (each dose containing a minimum of $4 \mathrm{IU}$ instead of $2 \cdot 1 \mathrm{IU}$ ) and in containing an adjuvant and strains of Bordetella pertussis that include the most prevalent serotype, type $1,3 .{ }^{9}$ In view of the introduction of these new vaccines it was decided to make regular comparisons of the notification rates in immunised and unimmunised children under 6 years of age. Data were provided by health authorities (see Appendix) who possessed the necessary computer facilities. These comparisons began in January 1972 and the results obtained up to the end of 1974 are reported here.

\section{Methods}

Each authority provided data on the pertussis immunisation received by each child under the age of 6 who suffered from whooping cough; the total number of children under 6 years in the area; and the number of children fully immunised against whooping cough in the area.

Children were considered to be fully immunised if they had received at least three doses of pertussis vaccine at the appropriate intervals. All other children, including those who had begun but not completed courses, were classified as not fully immunised. Most of the authorities made returns at the middle and end of each calendar year, but, owing to reorganisation, some areas were sometimes unable to supply the 
Whooping-cough notification rates according to period and immunisation state

\begin{tabular}{|c|c|c|c|c|c|c|c|}
\hline \multirow{2}{*}{ Period } & \multirow{2}{*}{ No of children } & \multicolumn{3}{|c|}{ Fully immunised } & \multicolumn{3}{|c|}{ Not fully immunised } \\
\hline & & No of children & No notified & Rate per 100000 & No of children & No notified & Rate per 100000 \\
\hline $\begin{array}{l}\text { Jan-June } 1972 \\
\text { July-Dec } 1972 \\
\text { Jan-June } 1973 \\
\text { July-Dec } 1973 \\
\text { Jan-June } 1974 \\
\text { July-Dec } 1974\end{array}$ & $\begin{array}{l}586708 \\
902717 \\
956705 \\
838589 \\
561066 \\
564893\end{array}$ & $\begin{array}{l}358609 \\
561621 \\
600120 \\
563618 \\
346072 \\
330344\end{array}$ & $\begin{array}{r}38 \\
32 \\
44 \\
87 \\
66 \\
165\end{array}$ & $\begin{array}{r}10 \cdot 6 \\
5.7 \\
7 \cdot 3 \\
15 \cdot 4 \\
19 \cdot 1 \\
50 \cdot 0\end{array}$ & $\begin{array}{l}228099 \\
341096 \\
356585 \\
324971 \\
214994 \\
234549\end{array}$ & $\begin{array}{r}45 \\
28 \\
67 \\
146 \\
107 \\
302\end{array}$ & $\begin{array}{r}19.7 \\
8.2 \\
18.8 \\
44.9 \\
49.8 \\
128.8\end{array}$ \\
\hline
\end{tabular}

data for more than one or two of the three years of the surveillance. Hence the total number of children included in the returns made after reorganisation in 1974 was less than in previous years.

\section{Results}

Among older children, in whom immunisation should have been completed, the proportion of fully immunised children remained reasonably constant-between $72 \%$ and $80 \%$-throughout the three years. This proportion was similar to the national average for pertussis immunisation. ${ }^{10}$

The number of notified cases in all areas combined and the notification rates among fully immunised and not fully immunised children in each six-monthly period are shown in the table. There were only a few notifications in the first three periods, but numbers increased from the second half of 1973 . This increase was in keeping with the increase in the numbers of national whooping-cough notifications at this time. The rates in each half year were greater among children who were not fully immunised than in those who were fully immunised: they were one and a half times to twice greater in 1972 and two and a half to three times greater in 1973 and 1974, when the notifications increased.

During the survey too few notifications were made in individual areas to enable useful comparisons to be made between areas. The number of cases in each age group notified each half year was also small, but in the 30 available comparisons by age and period there were four occasions when the rates were slightly greater among those who had been immunised. These immunised children were all born in 1968 and 1969 and some may have received the earlier, less effective, vaccine, and three of the four occasions when the trend was reversed were observed in the 1972 returns, when the number of notifications was particularly small and the inclusion of cases not due to $B$ pertussis would have the greatest effect in reducing the apparent efficacy of the vaccine. For children born after 1969 the whooping-cough notification rates were invariably greater in unimmunised children in every period and every age group. Cochran's method for combining $2 \times 2$ contingency tables was applied to test the overall difference between attack rates in the immunised and not fully immunised groups according to period and year of birth. This difference was significant well beyond the $0.01 \%$ level.

\section{Discussion}

Comparing the whooping-cough notification rates in children who are fully immunised and those who are not fully immunised is probably the only practicable method of keeping a routine check on the efficacy of pertussis vaccine, since the great effort required to make full-scale bacteriological and clinical surveys is unjustifiable when notification rates are small. While the type of comparison described here has the considerable advantage of simplicity and economy it has certain inherent drawbacks. For example, family doctors might tend to diagnose and notify whooping cough less often in immunised children than in unimmunised ones, and, moreover, children who are not fully immunised may come from different social backgrounds from those who are immunised; for example, they may come from larger families, where there may be a greater risk of exposure to whooping cough. On the other hand, bias against the efficacy of the vaccine would occur if, for example, general practitioners working in areas with a low rate of immunisation failed to notify cases. It has not yet been possible to study such causes of bias, although this aspect will be pursued as surveillance continues.

Although notifications of whooping cough reflect trends in the incidence of $B$ pertussis infection ${ }^{11}$ in most notifications the diagnosis is not bacteriologically confirmed. Thus some of the cases notified are probably due to organisms other than $B$ pertussis, against which whooping-cough vaccine would provide no protection. Consequently such infections would tend to be equally common in immunised and unimmunised children, and this would have the effect of reducing the apparent efficacy of the vaccine.

It is clear from the survey, however, that there is much less notified whooping cough in fully immunised children than in those who are not fully immunised, which suggests that the current vaccines confer appreciable protection on young children.

I thank the area health authorities who made the returns, Sir Austin Bradford Hill, FRS for his comments, and Mrs C E Owers and Mrs M Cable for their secretarial help.

\section{Appendix}

Health authorities who provided data for the study were: Bournemouth (Dorset AHA, Bournemouth East Dorset district), Buckinghamshire (before 1974 only), Carmarthen (before 1974 only), Cheshire (before 1974 only), Cornwall (Cornwall AHA), Coventry (before 1974 only), Cumberland (Cumbria AHA), Derbyshire AHA (1974 only), Devon (Devon AHA), Durham (Durham AHA), Hammersmith (Ealing, Hammersmith, and Hounslow AHA), Hampshire (Hampshire AHA), Huntingdon and Peterborough (Cambridgeshire AHA), Lancashire (Lancashire AHA), Leicestershire (Leicestershire AHA), Manchester (Manchester AHA), Newcastle upon Tyne (Newcastle upon Tyne AHA), North Riding of Yorkshire (before 1974 only), Northamptonshire (Northampton AHA), Somerset (Somerset AHA), West Sussex (West Sussex AHA), Teesside (Cleveland AHA), Torbay (Devon AHA, Torbay District), West Riding of Yorkshire (before 1974 only), and Wiltshire (before 1974 only).

\section{References}

${ }^{1}$ Medical Research Council, British Medical fournal, 1951, 1, 1463.

2 Medical Research Council, British Medical fournal, 1956, 2, 454.

${ }^{3}$ Medical Research Council, British Medical fournal, 1959, 1, 994.

${ }^{4}$ Wilson, A T, et al, British Medical fournal, 1965, 2, 623.

5 Preston, N W, British Medical fournal, 1963, 2, 724

6 Preston, N W, British Medical fournal, 1965, 2, 11.

7 Public Health Laboratory Service, British Medical fournal, 1969, 4, 329.

8 Public Health Laboratory Service, British Medical fournal, 1973, 1, 259.

9 Perkins, F T, British Medical fournal, 1969, 4, 429.

${ }_{10}$ Department of Health and Social Security; On the State of the Public Health. Annual Report of the Chief Medical Officer for the Year 1972, p 177. London, HMSO, 1973.

11 Public Health Laboratory Service, British Medical fournal, 1974, 3, 750. 